\title{
Effects of intrathecal bupivacaine on the NR2B/CaMKIIa/CREB signaling pathway in the rat lumbar spinal cord
}

\author{
LIYAN ZHAO $^{1}$, YONGHAI ZHANG ${ }^{2}$, FAN YANG $^{2}$, DI ZHU $^{1}$, NINGKANG LI ${ }^{1}$, \\ $\mathrm{LI} \mathrm{ZHAO}^{2}, \mathrm{NA} \mathrm{LI}^{1}$, JIANQIANG YU ${ }^{3 *}$ and HANXIANG MA ${ }^{2 *}$ \\ ${ }^{1}$ Department of Anesthesiology, Ningxia Medical University; ${ }^{2}$ Department of Anesthesiology, \\ General Hospital of Ningxia Medical University; ${ }^{3}$ Department of Pharmacology, \\ Ningxia Hui Medicine Modern Engineering Research Center and Collaborative Innovation Center, \\ Ningxia Medical University, Yinchuan, Ningxia 750004, P.R. China
}

Received August 22, 2017; Accepted December 12, 2017

DOI: $10.3892 / \mathrm{mmr} .2018 .8448$

\begin{abstract}
Neuraxial anesthesia produces an anestheticsparing, sedative effect. The mechanism underlying this effect potentially involves decreased spinal afferent input. However, the neurochemical mechanisms at the spinal level remain unknown. The $\mathrm{N}$-methyl-D-aspartate receptor 2B subunit/calcium-calmodulin-dependent protein kinase II $\alpha / c A M P$ response element-binding protein (NR2B/CaMKII $\alpha / C R E B$ ) signaling pathway serves an important role in regulating the transmittance of peripheral noxious stimulation to supraspinal regions in the process of nociception. The present study investigated the effects of intrathecal bupivacaine on the NR2B/CaMKII $\alpha / C R E B$ signaling pathway. Following catheterization, 36 male Sprague-Dawley rats were randomly assigned to a normal saline (NS) or bupivacaine treatment group, in which each rat intrathecally received $20 \mu \mathrm{l}$ normal saline or $0.5 \%$ bupivacaine, respectively. The expression levels of NR2B, CaMKII $\alpha / \mathrm{p}-\mathrm{CaMKII} \alpha$, and CREB/phosphorylated (p)-CREB in the lumbar spinal cord were investigated by western blotting, reverse transcription-quantitative polymerase chain reaction and immunohistochemistry (IHC). Following bupivacaine treatment, western blot analysis
\end{abstract}

Correspondence to: Professor Hanxiang Ma, Department of Anesthesiology, General Hospital of Ningxia Medical University, 804 Shengli Street, Yinchuan, Ningxia 750004, P.R. China

E-mail: mahanxiang@hotmail.com

Professor Jianqiang Yu, Department of Pharmacology, Ningxia Hui Medicine Modern Engineering Research Center and Collaborative Innovation Center, Ningxia Medical University, 692 Shengli Street, Yinchuan, Ningxia 750004, P.R. China

E-mail: yujqlab@163.com

*Contributed equally

Key words: anesthesia, sedation, N-methyl-D-aspartate receptor, calcium-calmodulin-dependent protein kinase II, cAMP response element-binding protein demonstrated that the protein expression levels of NR2B, $\mathrm{p}$-CaMKII $\alpha$, and p-CREB in the spinal cord were reduced by approximately 54,56 and $33 \%$, respectively, compared with NS control rats. Similar alterations in expression were observed by IHC analysis. Additionally, mRNA expression levels of NR2B, CaMKII $\alpha$, and CREB were also downregulated following the intrathecal administration of bupivacaine. Therefore, the sedative effect of subarachnoid blockade with bupivacaine possibly occurs through de-afferentation, which may reduce cortical arousal by downregulating the spinal NR2B/CaMKII $\alpha / C R E B$ pathway in vivo, however further investigation is required in order to verify this.

\section{Introduction}

Combined neuraxial and general anesthesia markedly reduces the sedative/anesthetic requirements of general anesthetics (1-3). Similar sensorial levels with neuraxial anesthesia reduce the need for propofol in similar amounts (4), and the high spinal blocking is associated with increased sedation (5). Previous studies have indicated that the sensorial levels of epidural and spinal anesthesia serve a key role in de-afferentation-dependent sedation. These findings have been verified by further studies, demonstrating that neuraxial anesthesia affects the degree of subcortical arousal via peripheral de-afferentation $(6,7)$. This may occur principally through the ablation of ascending nociceptive information transmission, which reduces arousal from surgical stimuli. A second subtle mechanism of neuraxial anesthesia may involve the blockade of motor and sensory activities, leading to reduced arousal even in the absence of any noxious stimuli (8-10).

Local anesthetics (LAs) including bupivacaine may not only block sodium channels, however may also affect synaptic transmission, modulate neurotransmitter release and interact with numerous other membrane proteins (11-13). These actions of LAs suggest that they may exert effects on glutamatergic synaptic transmission (11). Although sensory de-afferentation in the spinal cord may explain the sedative effect of neuraxial anesthesia, the neurochemical basis of de-afferentation-dependent sedation remains unknown. There is a lack of data on the neurochemical alterations that occur in the spinal cord 
following subarachnoid blockade with bupivacaine, particularly regarding synaptic transmission, which may be important for de-afferentation-dependent sedation during spinal anesthesia (14). In the transmission of somatosensory activity from the periphery to the brain, the N-methyl-D-aspartate (NMDA) subtype of glutamate receptors is considered to be essential $(15,16)$.

In the present study, subarachnoid bupivacaine blockade was hypothesized to produce a sensory de-afferentation by downregulating the $\mathrm{N}$-methyl-D-aspartate receptor $2 \mathrm{~B}$ subunit/calcium-calmodulin-dependentproteinkinaseII $\alpha / \mathrm{cAMP}$ response element-binding protein (NR2B/CaMKII $\alpha / C R E B)$ excitatory signaling pathway in the spinal cord. To test this hypothesis, the effect of intrathecal bupivacaine at clinically relevant concentrations was investigated on the expression levels of NR2B, CaMKII $\alpha / p-C a M K I I \alpha$, and CREB/p-CREB in rat lumbar spinal cord samples. The NR2B subunit of the NMDA receptor was investigated as it is considered to be specifically required for nociceptive afferents (16).

\section{Materials and methods}

Animals. The present study was approved by the Ethics Committee of Ningxia Medical University (Yinchuan, China). A total of 47 adult male Sprague-Dawley (SD) rats (weight, 280-320 g; age, 7-8 weeks) were obtained from the Animal Center of Ningxia Medical University. All of the procedures were performed in accordance with the National Institute of Health guidelines on animal care. Rats were housed in separate plastic cages with unlimited access to water and food, and kept in temperature-controlled rooms $\left(20-24^{\circ} \mathrm{C}\right.$, relative humidity $50-60 \%$ ) under a $12 / 12 \mathrm{~h}$ light/dark cycle (with the dark cycle beginning at 7:00 p.m.). All experiments were conducted during light hours.

Catheter modification and intrathecal catheter placement. Rats were allowed to acclimate to the laboratory environment for 3 days. A rat model of intrathecal catheterization was established as previously described (17). To construct the intrathecal catheter, sections of polyethylene tubing of sizes PE-20 $(8 \mathrm{~cm})$ and PE-10 $(2 \mathrm{~cm})$ were connected to each other to produce a catheter with a decreasing diameter profile. Animals were anesthetized with an intraperitoneal (i.p.) injection of pentobarbital sodium at a dose of $60 \mathrm{mg} \mathrm{kg}^{-1}$. A longitudinal $1.5-\mathrm{cm}$ incision was made in the lumbar $\mathrm{L}_{4}-\mathrm{L}_{5}$ vertebra of each rat placed in a prone position. One end of the small profiled catheter was inserted into the subarachnoid space through the incision, while the other was tunneled subcutaneously toward the occiput, exposing the distal tip out of the neck skin. Cefazolin sodium $(100 \mathrm{mg})$ was injected intramuscularly to prevent infection. Following $24 \mathrm{~h}$ of catheterization, all rats with any sign of neurological deficit, infection, catheter displacement, or clogging, and those without bilateral lower extremity paralysis following intrathecal injection of $15 \mu 1$ 2\% lidocaine (Yinhu Shiyao Pharmaceutical Co, Ltd., Yuncheng, Shanxi, China) within $5 \mathrm{~min}$, were excluded from the study.

Treatment groups. Following catheterization, 36 male SD rats were included and assigned to a normal saline (NS) group ( $n=18)$ or a bupivacaine (Bup) group $(n=18)$. Each rat was intrathecally administered once with $20 \mu \mathrm{l}$ saline solution or $0.5 \%$ bupivacaine (Shanghai Zhaohui Pharmaceutical Co, Ltd., Shanghai, China) and injected for $10 \mathrm{sec}$. From each group, samples from six rats were used for western blotting, samples from another six rats were used for reverse transcription-quantitative polymerase chain reaction (RT-qPCR), and samples from the remaining six rats were used for immunohistochemical (IHC) analysis.

Western blot analysis. Following $10 \mathrm{~min}$ of intrathecal administration of bupivacaine or saline, the rats were sacrificed by spinal dislocation. The lumbar enlargement of the spinalrd, which was estimated to be in the $\mathrm{L}_{1}-\mathrm{L}_{5}$ region (18), was collected and homogenized in lysis buffer (Nanjing KeyGEN Biotech, Co., Ltd., Nanjing, China). The homogenate was centrifuged at $4^{\circ} \mathrm{C}$ and $14,000 \times \mathrm{g}$ for $15 \mathrm{~min}$. The supernatant (50 $\mu \mathrm{g}$ per sample, as quantified by a bicinchoninic acid protein assay kit (Nanjing KeyGEN Biotech, Co., Ltd.) was separated on $8 \%$ SDS-PAGE and transferred onto nitrocellulose membranes (GE Healthcare Bio-Sciences, Pittsburgh, PA, USA). Following incubation in 5\% non-fat milk for $2 \mathrm{~h}$ at room temperature, membranes were incubated with primary antibodies against GAPDH (10494-1-AP; 1:2,000; ProteinTech Group, Inc., Chicago, IL, USA), NR2B (21920-1-AP; 1:1,000; ProteinTech Group, Inc.), CaMKII $\alpha$ (13730-1-AP; 1:1,000; ProteinTech Group, Inc.), CREB (9197; 1:900; Cell Signaling Technology, Inc., Danvers, MA, USA), phosphorylated (p)-CaMKII $\alpha$ (11278; 1:700; Signal-Aldrich; Merck KGaA, Darmstadt, Germany), and p-CREB (9198; 1:600; Cell Signaling Technology, Inc., USA) at $4^{\circ} \mathrm{C}$ overnight. Following washing, the membranes were incubated at room temperature for $2 \mathrm{~h}$ with secondary antibody (goat anti-rabbit IgG, SA00001-2; 1:2,000; ProteinTech Group, Inc.). Following washing with TBS with Tween-20, blots were visualized with an enhanced chemiluminescence kit (32109; Pierce; Thermo Fisher Scientific, Inc., Waltham, MA, USA) and subsequently analyzed densitometrically with a western blotting detection system (Quantity One software version 4.6.2; Bio-Rad Laboratories, Inc., Hercules, CA, USA). Results were normalized to the protein level of GAPDH in each sample.

Quantification of the spinal cord mRNA expression levels. RT-qPCR analysis was conducted following a previously described method (19). Total RNA from the spinal cord $\left(\mathrm{L}_{1}-\mathrm{L}_{5}\right)$ tissue was isolated with a Total RNA Miniprep Kit (Axygen A; Corning Incorporated, Corning, NY, USA) and reverse transcribed into cDNA (TransGen Biotech, China). Primer sequences used for PCR are presented in Table I. PCR was performed in a Light Cycler system (qTOWER 2.0; Analytic Jena AG, Jena, Germany), using SYBR Green I dye (TransGen Biotech, Beijing, China) to detect the mRNA expression levels of NR2B, CaMKII $\alpha$, CREB, and GAPDH. The cDNA products $(3.5 \mu \mathrm{l}), 10 \mu \mathrm{M}$ forward primer $(1 \mu \mathrm{l}), 10 \mu \mathrm{M}$ reverse primer $(1 \mu \mathrm{l})$, and 2XTransStart Top Green qPCR SuperMix (12.5 $\mu \mathrm{l})$ were mixed and added with double distilled water to obtain a total reaction volume of $25 \mu$ l. The reaction conditions were $50^{\circ} \mathrm{C}$ for $2 \mathrm{~min}, 95^{\circ} \mathrm{C}$ for $10 \mathrm{~min}$, and 40 cycles of $30 \mathrm{sec}$ at $94^{\circ} \mathrm{C}$ and $30 \mathrm{sec}$ at $60^{\circ} \mathrm{C}$. Data were analyzed by the $2^{-\Delta \Delta \mathrm{Cq}}$ method, using GAPDH as a reference gene (20). 
Table I. Primer sequences and annealing temperatures.

Annealing

Primer

Forward sequence (5'-3')

Reverse sequence (5'-3')

\begin{tabular}{llll}
\hline GAPDH & ACAGCAACAGGGTGGTGGAC & TTTGAGGGTGCAGCGAACTT & 59 \\
NR2B & CCTTCCTGCCAGAGTGAGAG & CCTCTTCTCGTGGGTGTTGT & 60 \\
CaMKII & CTGAACCCTCACATCCACCT & ACACGGGTCTCCTCTGACTG & 59 \\
CREB & CATGGACTCTGGAGCAGACA & CTGGGCTAATGTGGCAATCT & 57 \\
\hline
\end{tabular}

NR2B, N-methyl-D-aspartate receptor subunit B; CaMKII, calcium/calmodulin-dependent protein kinase II; CREB, cAMP-response element-binding protein.

A

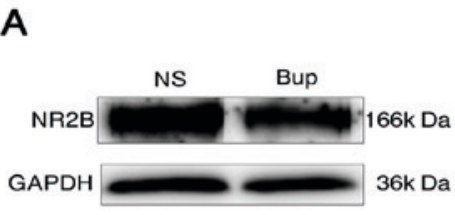

C

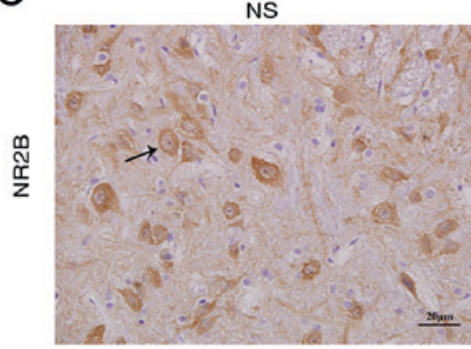

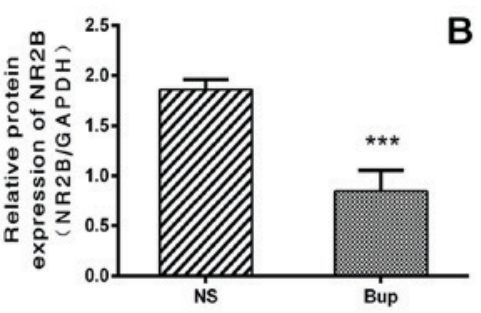

Bup

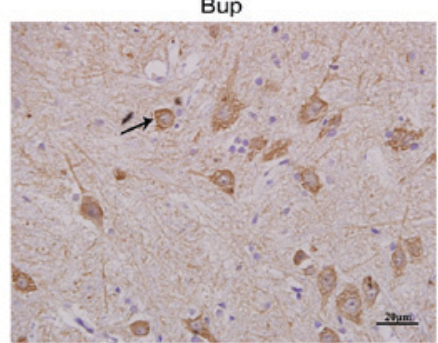

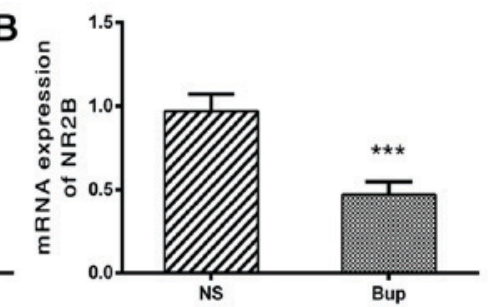

NS

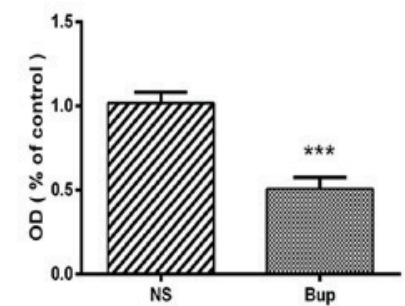

Figure 1. Intrathecal bupivacaine reduces the expression of NR2B in rat spinal cord tissue. (A) Protein expression of NR2B as measured by western blot analysis; (B) mRNA expression of NR2B as measured by reverse transcription-quantitative polymerase chain reaction; (C) Protein expression of NR2B as measured by immunohistochemistry (magnification, $\mathrm{x} 400$ ). Data are expressed as the mean \pm standard deviation of six rats in each group. ${ }^{* * *} \mathrm{P}<0.001 \mathrm{vs.}$ the NS group. Bup, bupivacaine; NR2B, N-methyl-D-aspartate receptor subunit B; NS, normal saline; OD, optical density.

IHC analysis. Under deep anesthesia with sodium pentobarbital at a dose of $60 \mathrm{mg} \mathrm{kg}^{-1}$, six male SD rats from each experimental group were transcardially perfused with $500 \mathrm{ml}$ NS, followed by $500 \mathrm{ml} \mathrm{4 \%}$ paraformaldehyde in PBS. The spinal cord was removed and post-fixed in $10 \%$ formalin solution for $12 \mathrm{~h}$ at $4^{\circ} \mathrm{C}$. All samples were embedded in paraffin and transversely cut into $4-\mu \mathrm{m}$ thick sections with a sliding microtome. Following deparaffinization and hydration, sections were blocked in $3 \% \mathrm{H}_{2} \mathrm{O}_{2}$ for $10 \mathrm{~min}$ at room temperature, and were incubated with primary antibodies, including anti-NR2B (ab216621; 1:250; Abcam, Cambridge, UK), anti-p-CaMKII $\alpha$ (ab5683; 1:300; Abcam), and anti-p-CREB (9198; 1:700; Cell Signaling Technology, Inc.), for $2 \mathrm{~h}$ at $37^{\circ} \mathrm{C}$. Slides were washed with 0.1 M PBS 3 times for 2 min and subsequently incubated with a goat anti-rabbit secondary antibody (PV-9001; 1:500; ZSGB-BIO; OriGene Technologies, Inc., Rockville, MD, USA) for $30 \mathrm{~min}$ at $37^{\circ} \mathrm{C}$, then stained with diaminobenzidine (DAB kit; ZSGB-BIO; OriGene Technologies, Inc.) and counterstained with hematoxylin for $30 \mathrm{sec}$ at room temperature. Images were captured with a light microscope (Olympus Corporation, Tokyo, Japan). Quantitative image analysis of the relative optical density (OD) was performed using Image Pro
Plus software version 6.0 (Media Cybernetics, Inc., Rockville, MD, USA).

Statistical analysis. All analyses were performed with SPSS software, version 17.0 (SPSS, Inc., Chicago, IL, USA). All parametric data were presented as the mean \pm standard deviation. Comparisons between the two groups were performed with independent samples t-tests. $\mathrm{P}<0.05$ was considered to indicate a statistically significant difference.

\section{Results}

Of the $47 \mathrm{SD}$ rats intrathecally catheterized, 36 were included in the experiments. Of the rats excluded, five exhibited a neurological deficit and six exhibited failed catheterization.

Intrathecal bupivacaine decreases $N R 2 B$ expression in the spinal cord. Following the intrathecal administration of bupivacaine, protein and mRNA expression levels of NR2B were decreased by $\sim 54$ and $51 \%$, respectively, compared with the NS rat group (Fig. 1A and $\mathrm{B} ; \mathrm{P}<0.001$ ). This was further verified by IHC analysis, which demonstrated that the NR2B protein 

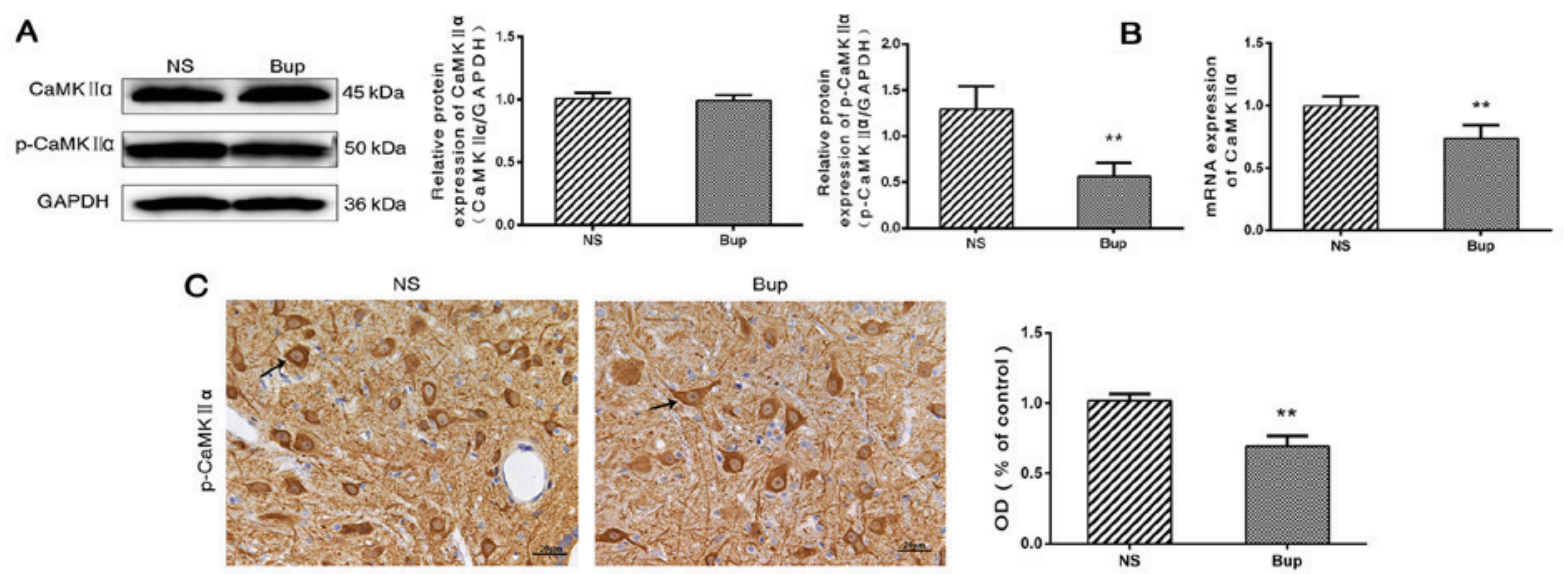

Figure 2. Intrathecal bupivacaine reduces the expression of p-CaMKII $\alpha$ in rat spinal cord tissue. (A) Protein expression of CaMKII $\alpha / \mathrm{p}$-CaMKII $\alpha$ as measured by western blot analysis; (B) mRNA expression of CaMKII $\alpha$ as measured by reverse transcription-quantitative polymerase chain reaction; (C) Protein expression of $\mathrm{p}$-CaMKII $\alpha$ as measured by immunohistochemistry (magnification, $\mathrm{x} 400$ ). Data are expressed as the mean \pm standard deviation of six rats in each group. ${ }^{* *} \mathrm{P}<0.01$ vs. the NS group. CaMKII, calcium/calmodulin-dependent protein kinase II; p, phosphorylated; Bup, bupivacaine; NS, normal saline; OD, optical density.
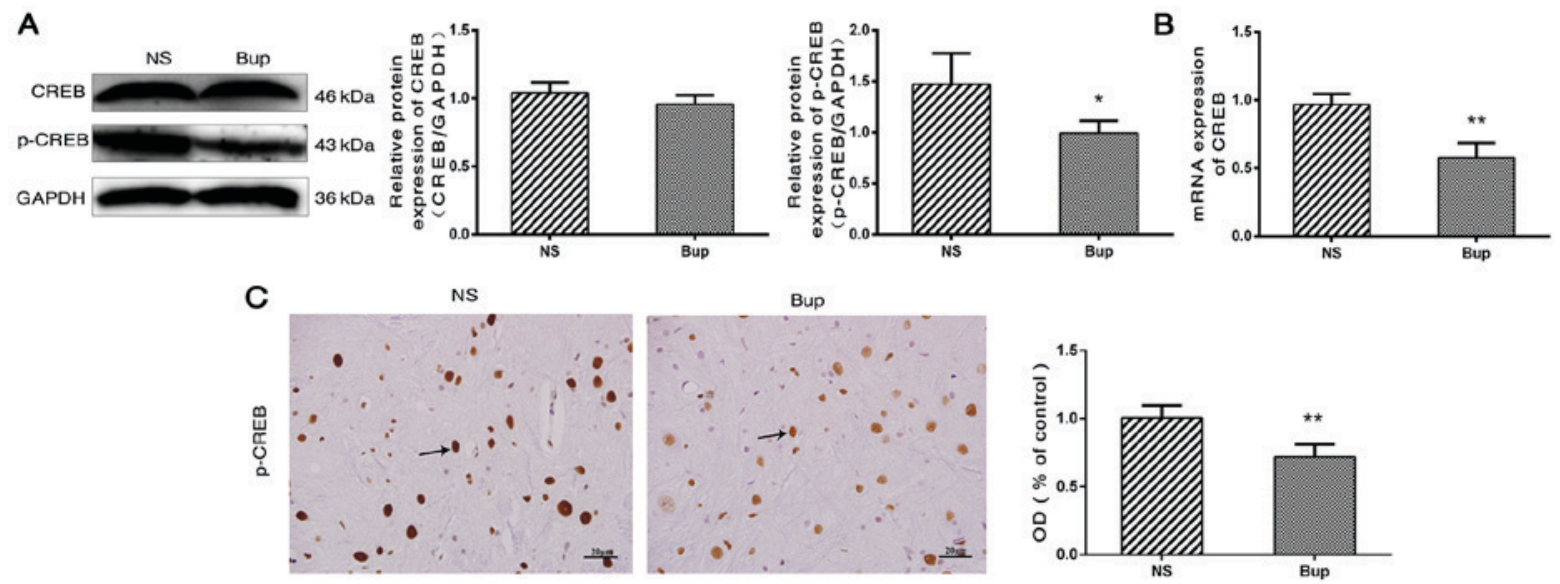

Figure 3. Intrathecal bupivacaine reduces the expression of p-CREB in rat spinal cord tissue. (A) Protein expression of CREB/p-CREB as measured by western blot analysis; (B) mRNA expression of CREB as measured by reverse transcription-quantitative polymerase chain reaction; (C) Protein expression of p-CREB as measured by immunohistochemistry (magnification, $\mathrm{x} 400$ ). Values are expressed as the mean \pm standard deviation of six rats in each group. ${ }^{*} \mathrm{P}<0.05$ and ${ }^{* *} \mathrm{P}<0.01$ vs. the NS group. Bup, bupivacaine; CREB, cAMP-response element-binding protein; NS, normal saline; OD, optical density; p, phosphorylated.

expression was decreased by $\sim 50 \%$ in the spinal cord tissues following bupivacaine treatment (Fig. 1C; $<<0.001$ ). Together these observations indicated that the decreased expression of NR2B is associated with subarachnoid bupivacaine blockade.

Effect of intrathecal bupivacaine on CaMKIIa and p-CaMKIIa levels in the spinal cord. Western blotting revealed that the protein expression level of total CaMKII $\alpha$ in the spinal cord did not differ between the Bup and NS groups (Fig. 2A; $\mathrm{P}>0.05$ ). Compared with the NS group, the mRNA level of CaMKII $\alpha$ was reduced by $\sim 36 \%$ in the Bup group (Fig. 2B; $\mathrm{P}<0.01)$. Western blotting and IHC indicated that the protein expression levels of p-CaMKII $\alpha$ were decreased by $\sim 56$ and $32 \%$, respectively in the Bup group compared with the NS group (Fig. 2A and $\mathrm{C} ; \mathrm{P}<0.01$ ).

Effect of intrathecal bupivacaine on CREB and p-CREB levels in the spinal cord. Based on the results of western blot analysis, the alterations in the expression of CREB in the spinal cord were similar to those of CaMKIIa (Fig. 3A; $\mathrm{P}>0.05)$. Compared with the NS group, mRNA levels of CREB were reduced by $\sim 41 \%$ in the Bup group (Fig. 3B; $\mathrm{P}<0.01)$. The protein expression level of $\mathrm{p}$-CREB was indicated to be decreased by $\sim 33$ and $28 \%$ by western blotting and IHC, respectively in the Bup group, compared with the NS group (Fig. 3A and $\mathrm{C} ; \mathrm{P}<0.05$ and $\mathrm{P}<0.01$ ).

\section{Discussion}

Sedation during neuraxial blockade was highlighted in 1994 when Tverskoy et al (21) reported that subarachnoid blockade with bupivacaine reduces the hypnotic requirements of midazolam and thiopental. In animal (22) and clinical studies $(23,24)$, these findings were verified, and neuraxial blocking was reported to elicit sedative effects. While the neurochemical mechanism underlying the reduced requirement 
for general anesthetic remains poorly understood at the spinal level, the systemic general anesthetic effects of absorbed local anesthetics (25) and de-afferentation (26) have been revealed to be mechanisms that may explain the interaction between local and general anesthetics. The afferentation theory suggests that tonic sensory and muscle-spindle activities maintain a state of wakefulness $(26,27)$. For de-afferentation, neuraxial anesthesia reduces the spinal afferent input and thus affects the level of consciousness, enabling decreases in subsequent doses of the agent to achieve a defined level of sedation (27). The most speculated mechanism for sedation during neuraxial anesthesia is the de-afferentation phenomenon, which affects sensitivity to sedative/anesthetic drugs. Additionally, afferent somatosensory information, particularly nociceptive information, considerably affects brain activity $(28,29)$. Complete spinal cord transection immediately slows down cortical electroencephalogram activity $(30,31)$. Similarly, the degree of subcortical arousal is significantly affected when spinal and epidural blocking reduce or prevent afferent inputs from the blocked region of the body to the brain. However, the potential neurochemical mechanisms involved remain unknown.

The effect of subarachnoid bupivacaine blockade on the NMDA receptor subunit NR2B and its associated signal transduction pathway were investigated in the lumbar spinal cord of rats, using bupivacaine at clinically relevant concentrations. NR2B, p-CaMKII $\alpha$, and p-CREB were considerably downregulated following intrathecal administration of bupivacaine. Similar alterations in expression were observed by IHC analysis. Based on the current findings, it may be suggested that the sedative effect of subarachnoid bupivacaine blockade is associated with a decrease in spinal afferent input, possibly due to the downregulation of NR2B, p-CaMKII $\alpha$, and p-CREB expression levels in the lumbar spinal cord.

Glutamate acts as an excitatory neurotransmitter in primary afferent terminals and serves a critical role in spinal synaptic transmission through its activation of glutamate receptors (32). NMDA receptors are glutamate receptors in the central nervous system. The binding of glutamate to the NMDA receptor results in an influx of extracellular $\mathrm{Ca}^{2+}$, which controls membrane excitability and synaptic transmission (33). CaMKII $\alpha$ is a multifunctional serine/threonine protein kinase, which is activated when cytosolic $\mathrm{Ca}^{2+}$ increases and in the presence of peripheral pain stimuli, CaMKII $\alpha$ is phosphorylated at Thr286 (p-CaMKII $\alpha$ ) in the spinal cord (34). The p-CaMKII $\alpha$ then translocates to the nucleus where it phosphorylates CREB at Ser133 in the dorsal horn of the spinal cord. Subsequently, p-CREB initiates gene transcription and translation and is thus possibly involved in the ascending transmission of nociceptive information. Peripheral nociceptive information, including visceral, inflammatory, and neuropathic pain, may activate NR2B, $\mathrm{p}$-CaMKII $\alpha$, and p-CREB and may facilitate nociceptive transmission in the spinal cord. Therefore, reduced expression of NR2B, p-CaMKII $\alpha$, and p-CREB may suppress various types of hyperalgesia, including inflammatory pain $(35,36)$, neuropathic pain (36-39), opioid-induced hyperalgesia (40), visceral pain (41-43), and central pain (44-46). A key step in the transmission of nociceptive information from the spinal cord to the brain is the activation of NMDA receptors in the spinal dorsal horn neurons (47). This suggests that ascending nociceptive transmission may be reduced by downregulating NMDA receptor expression and the associated signal transduction pathways. Furthermore, bupivacaine inhibits NMDA-induced glutamatergic transmission in rat dorsal horn neurons $(48,49)$. This result is concordant with the present results. In the present study, spinally administered bupivacaine was indicated to inhibit NMDA-induced glutamatergic transmission in the spinal cord through downregulation of NR2B, p-CaMKII $\alpha$, and p-CREB.

Several important limitations were noted in the current study. Firstly, although protein and mRNA expression levels of NR2B, p-CaMKII $\alpha$, and p-CREB were all downregulated following intrathecal bupivacaine, the results indirectly indicate that the NR2B/CaMKII $\alpha / C R E B$ signaling pathway is involved in sedation during spinal anesthesia. Therefore, future studies are necessary in order to verify the association between sedation during spinal anesthesia and NR2B/CaMKII $\alpha / C R E B$ signaling by using agonists or antagonists. Secondly, the results demonstrated that expression levels of total CaMKII $\alpha$, and CREB mRNA were decreased, although the levels of their protein expression were not altered following intrathecal bupivacaine. The association between mRNA and protein expression is not strictly linear, however has a more intrinsic and complex dependence (50). Therefore, this variation may be due to post-transcriptional and post-translation regulation and experimental errors $(50,51)$. Thirdly, the upstream and downstream molecules of NR2B/CaMKIIa/CREB were not detected. Future studies may elucidate the function of these molecular components.

In conclusion, sedation during spinal anesthesia from decreased spinal afferent input may be associated with the downregulation of NR2B, p-CaMKII $\alpha$, and p-CREB expression levels in the spinal cord. Therefore, stimulatory input to the brain may be indirectly reduced by inhibiting the NR2B/CaMKII $/$ /CREB signaling pathway in spinal neurons, with this inhibition rendering the brain susceptible to the effects of sedative drugs. The present findings may prompt anesthesiologists to plan appropriate dosage guidelines for the prevention of anesthetic overdose and investigate the mechanism of sedation during neuraxial anesthesia.

\section{Acknowledgements}

The present study was supported by the National Natural Science Foundation of China (grant no. 81660198) and Ningxia Natural Science Foundation (grant. no. NZ15137).

\section{References}

1. Kim SH, Chun DH, Chang CH, Kim TW, Kim YM and Shin YS: Effect of caudal block on sevoflurane requirement for lower limb surgery in children with cerebral palsy. Paediatr Anaesth 21: 394-398, 2011.

2. Xiang Y, Chen CQ, Chen HJ, Li M, Bao FP and Zhu SM: The effect of epidural lidocaine administration on sedation of propofol general anesthesia: A randomized trial. J Clin Anesth 26: 523-529, 2014.

3. Zhang J, Zhang W and Li B: The effect of epidural anesthesia with different concentrations of ropivacaine on sevoflurane requirements. Anesth Analg 104: 984-986, 2007. 
4. Sentürk M, Gücyetmez B, Ozkan-Seyhan T, Karadeniz M, Dinçer S, Akpir D, Sengül T and Denkel T: Comparison of the effects of thoracic and lumbar epidural anaesthesia on induction and maintenance doses of propofol during total i.v. anaesthesia. Br J Anaesth 101: 255-260, 2008.

5. Gentili M, Huu PC, Enel D, Hollande J and Bonnet F: Sedation depends on the level of sensory block induced by spinal anaesthesia. Br J Anaesth 81: 970-971, 1998.

6. Pollock JE, Neal JM, Liu SS, Burkhead D and Polissar N: Sedation during spinal anesthesia. Anesthesiology 93: 728-734, 2000.

7. Yang W, Geng Y, Liu Y, Li A, Liu J, Xing J and Li W: Comparison of effects of thoracic epidural and intravenous administration of lidocaine on target-controlled infusion of propofol and tracheal intubation response during induction of anesthesia. J Cardiothorac Vasc Anesth 27: 1295-1300, 2013.

8. Hodgson PS and Liu SS: Epidural lidocaine decreases sevoflurane requirement for adequate depth of anesthesia as measured by the Bispectral Index monitor. Anesthesiology 94: 799-803 2001.

9. Doufas AG, Wadhwa A, Shah YM, Lin CM, Haugh GS and Sessler DI: Block-dependent sedation during epidural anaesthesia is associated with delayed brainstem conduction. Br J Anaesth 93: 228-234, 2004

10. Antognini JF, Atherley R and Carstens E: Isoflurane action in spinal cord indirectly depresses cortical activity associated with electrical stimulation of the reticular formation. Anesth Analg 96: 999-1003, 2003

11. Lin TY, Chung CY, Lu CW, Huang SK, Shieh JS and Wang SJ: Local anesthetics inhibit glutamate release from rat cerebral cortex synaptosomes. Synapse 67: 568-579, 2013.

12. Cherng CH, Wong CS, Wu CT and Yeh CC: Glutamate release and neurologic impairment after intrathecal administration of lidocaine and bupivacaine in the rat. Reg Anesth Pain Med 36 452-456, 2011

13. Nishizawa N, Shirasaki T, Nakao S, Matsuda H and Shingu K The inhibition of the N-methyl-D-aspartate receptor channel by local anesthetics in mouse CA1 pyramidal neurons. Anesth Analg 94: 325-330, 2002.

14. Lanier WL, Iaizzo PA, Milde JH and Sharbrough FW: The cerebral and systemic effects of movement in response to a noxious stimulus in lightly anesthetized dogs. Possible modulation of cerebral function by muscle afferents. Anesthesiology 80 392-401, 1994

15. Zhai QZ and Traub RJ: The NMDA receptor antagonist MK-801 attenuates c-Fos expression in the lumbosacral spinal cord following repetitive noxious and non-noxious colorectal distention. Pain 83: 321-329, 1999.

16. Tong CK and MacDermott AB: Synaptic GluN2A and GluN2B containing NMDA receptors within the superficial dorsal horn activated following primary afferent stimulation. J Neurosci 34 10808-10820, 2014.

17. Saito Y, Kaneko M, Kirihara Y, Sakura S and Kosaka Y: Interaction of intrathecally infused morphine and lidocaine in rats (part I): Synergistic antinociceptive effects. Anesthesiology 89 1455-1463, 1998

18. Oklinski MK, Lim JS, Choi HJ, Oklinska P, Skowronski MT and Kwon TH: Immunolocalization of water channel proteins AQP1 and AQP4 in rat spinal cord. J Histochem Cytochem 62: 598-611, 2014.

19. Wang HL, Li YX, Niu YT, Zheng J, Wu J, Shi GJ, Ma L, Niu Y, Sun T and Yu JQ: Observing anti-inflammatory and anti-nociceptive activities of glycyrrhizin through regulating COX-2 and pro-inflammatory cytokines expressions in mice. Inflammation 38: 2269-2278, 2015.

20. Livak KJ and Schmittgen TD: Analysis of relative gene expression data using real-time quantitative PCR and the $2^{-\Delta \Delta C_{\mathrm{T}}}$ method Methods 25: 402-408, 2001.

21. Tverskoy M, Shagal M, Finger J and Kissin I: Subarachnoid bupivacaine blockade decreases midazolam and thiopental hypnotic requirements. J Clin Anesth 6: 487-490, 1994.

22. Eappen S and Kissin I: Effect of subarachnoid bupivacaine block on anesthetic requirements for thiopental in rats. Anesthesiology 88: 1036-1042, 1998.

23. Agarwal A, Pandey R, Dhiraaj S, Singh PK, Raza M, Pandey CK, Gupta D, Choudhury A and Singh U: The effect of epidural bupivacaine on induction and maintenance doses of propofol (evaluated by bispectral index) and maintenance doses of fentanyl and vecuronium. Anesth Analg 99: 1684-1688, 2004.
24. Ingelmo PM, Ferri $F$ and Fumagalli R: Interactions between general and regional anesthesia. Minerva Anestesiol 72: 437-445, 2006.

25. Inagaki Y, Mashimo T, Kuzukawa A, Tsuda Y and Yoshiya I: Epidural lidocaine delays arousal from isoflurane anesthesia. Anesth Analg 79: 368-372, 1994.

26. Foffani G, Humanes-Valera D, Calderon-Muñoz F, Oliviero A and Aguilar J: Spinal cord injury immediately decreases anesthetic requirements in rats. Spinal Cord 49: 822-826, 2011.

27. Hodgson PS, Liu SS and Gras TW: Does epidural anesthesia have general anesthetic effects? A prospective, randomized, double-blind, placebo-controlled trial. Anesthesiology 91: $1687-1692,1999$.

28. Antognini JF and Carstens E: Isoflurane blunts electroencephalographic and thalamic-reticular formation responses to noxious stimulation in goats. Anesthesiology 91: 1770-1779, 1999.

29. Antognini JF, Carstens E, Sudo M and Sudo S: Isoflurane depresses electroencephalographic and medial thalamic responses to noxious stimulation via an indirect spinal action. Anesth Analg 91: 1282-1288, 2000.

30. Aguilar J, Humanes-Valera D, Alonso-Calviño E, Yague JG, Moxon KA, Oliviero A and Foffani G: Spinal cord injury immediately changes the state of the brain. J Neurosci 30: 7528-7537, 2010.

31. Alonso-Calviño E, Martinez-Camero I, Fernández-López E, Humanes-Valera D, Foffani G and Aguilar J: Increased responses in the somatosensory thalamus immediately after spinal cord injury. Neurobiol Dis 87: 39-49, 2016.

32. Aanonsen LM and Wilcox GL: Nociceptive action of excitatory amino acids in the mouse: Effects of spinally administered opioids, phencyclidine and sigma agonists. J Pharmacol Exp Ther 243: 9-19, 1987

33. Tang Q, Bangaru ML, Kostic S, Pan B, Wu HE, Koopmeiners AS, $\mathrm{Yu} \mathrm{H}$, Fischer GJ, McCallum JB, Kwok WM, et al: $\mathrm{Ca}^{2+}$-dependent regulation of $\mathrm{Ca}^{2+}$ currents in rat primary afferent neurons: Role of CaMKII and the effect of injury. J Neurosci 32: 11737-11749, 2012.

34. Zeitz KP, Giese KP, Silva AJ and Basbaum AI: The contribution of autophosphorylated alpha-calcium-calmodulin kinase II to injury-induced persistent pain. Neuroscience 128: 889-898, 2004.

35. Nakanishi M, Hata K, Nagayama T, Sakurai T, Nishisho T, Wakabayashi H, Hiraga T, Ebisu S and Yoneda T: Acid activation of Trpvl leads to an up-regulation of calcitonin gene-related peptide expression in dorsal root ganglion neurons via the CaMK-CREB cascade: A potential mechanism of inflammatory pain. Mol Biol Cell 21: 2568-2577, 2010

36. Descalzi G, Fukushima H, Suzuki A, Kida S and Zhuo M: Genetic enhancement of neuropathic and inflammatory pain by forebrain upregulation of CREB-mediated transcription. Mol Pain 8: 90, 2012.

37. Miletic G, Pankratz MT and Miletic V: Increases in the phosphorylation of cyclic AMP response element binding protein (CREB) and decreases in the content of calcineurin accompany thermal hyperalgesia following chronic constriction injury in rats. Pain 99: 493-500, 2002.

38. Ma W, Hatzis C and Eisenach JC: Intrathecal injection of cAMP response element binding protein (CREB) antisense oligonucleotide attenuates tactile allodynia caused by partial sciatic nerve ligation. Brain Res 988: 97-104, 2003.

39. Katano T, Nakazawa T, Nakatsuka T, Watanabe M, Yamamoto T and Ito S: Involvement of spinal phosphorylation cascade of Tyr1472-NR2B, Thr286-CaMKII, and Ser831-GluR1 in neuropathic pain. Neuropharmacology 60: 609-616, 2011

40. Wang Z, Ma W, Chabot JG and Quirion R: Calcitonin generelated peptide as a regulator of neuronal CaMKII-CREB, microglial p38-NFKB and astroglial ERK-Stat1/3 cascades mediating the development of tolerance to morphine-induced analgesia. Pain 151: 194-205, 2010.

41. Wang Y, Wu J, Lin Q, Nauta HJ, Yue Y and Fang L: Effects of general anesthetics on visceral pain transmission in the spinal cord. Mol Pain 4: 50, 2008

42. Pan X, Chen J, Wang W, Chen L, Wang L, Ma Q, Zhang J, Chen L, Wang G, Zhang M, et al: Resveratrol-induced antinociception is involved in calcium channels and calcium/caffeine-sensitive pools. Oncotarget 8: 9399-9409, 2017.

43. Miranda A, Mickle A, Bruckert M, Kannampalli P, Banerjee B and Sengupta JN: NMDA receptor mediates chronic visceral pain induced by neonatal noxious somatic stimulation. Eur J Pharmacol 744: 28-35, 2014. 
44. Crown ED, Gwak YS, Ye Z, Yu Tan H, Johnson KM, Xu GY, McAdoo DJ and Hulsebosch CE: Calcium/calmodulin dependent kinase II contributes to persistent central neuropathic pain following spinal cord injury. Pain 153: 710-721, 2012.

45. Fang L, Wu J,Zhang X,Lin Q and Willis WD: Calcium/calmodulin dependent protein kinase II regulates the phosphorylation of cyclic AMP-responsive element-binding protein of spinal cord in rats following noxious stimulation. Neurosci Lett 374: $1-4,2005$.

46. Mitsikostas DD, Knight YE, Lasalandra M, Kavantzas N and Goadsby PJ: Triptans attenuate capsaicin-induced CREB phosphorylation within the trigeminal nucleus caudalis: A mechanism to prevent central sensitization? J Headache Pain 12: 411-417, 2011.

47. Liu H, Zhang Y, Qi D and Li W: Downregulation of the spinal NMDA receptor NR2B subunit during electro-acupuncture relief of chronic visceral hyperalgesia. J Physiol Sci 67: 197-206, 2017.
48. Paganelli MA and Popescu GK: Actions of bupivacaine, a widely used local anesthetic, on NMDA receptor responses. J Neurosci 35: 831-842, 2015

49. Furutani K, Ikoma M, Ishii H, Baba $\mathrm{H}$ and Kohno T: Bupivacaine inhibits glutamatergic transmission in spinal dorsal horn neurons. Anesthesiology 112: 138-143, 2010

50. de Sousa Abreu R, Penalva LO, Marcotte EM and Vogel C: Global signatures of protein and mRNA expression levels. Mol Biosyst 5: 1512-1526, 2009.

51. Fraser HB, Hirsh AE, Giaever G, Kumm J and Eisen MB: Noise minimization in eukaryotic gene expression. PLoS Biol 2: e137, 2004.

This work is licensed under a Creative Commons Attribution-NonCommercial-NoDerivatives 4.0 International (CC BY-NC-ND 4.0) License. 